\title{
Reform on the Curriculum Teaching Mode of the Dynamic Modular Curriculum Driven by the Typical Working-task for the Speciality of Tourism Higher Vocational College ---A Case of Curriculum Tour Guiding Practices
}

\author{
Yunqin Liu \\ Humanity tourism department of Hunan vocational college of commerce, Changsha, Hunan, \\ 410205, China \\ Lyq521125@126.com
}

Keywords: Typical work-task driven; The dynamic modular; Curriculum teaching mode; Reform; Tourism speciality in higher vocational college

Abstract. The in-depth analysis is performed on the course. The practices of tour guide of the Tourism speciality in higher vocational college. And the curriculum teaching dynamic knowledge and competence models is constructed with the talent cultivating goal and the courses teaching goal is set up, on the basis of the traditional curriculum modular is broken and the teaching designed is completed, the new dynamic curriculum teaching mode is reconstructed driven by the typical work-task in the practical guiding work, thus, it provides the reference and the practical mode for the reform for the curriculum of the Tourism speciality in the higher vocational college.

\section{典型工作任务驱动的高职旅游专业动态模块式教 学模式改革----以《导游实务》为例}

刘韵琴

湖南商务职业技术学院人文旅游学院，中国 湖南 长沙 410205

Lyq521125@126.com

摘要: 以高职旅游专业主干课程《导游实务》为例, 对高职旅游类专业课程教学现状进行了 深入的分析。以导游职业行动领域的典型工作任务导游服务为驱动, 从专业人才培养定位、 课程目标明确、学习任务设计出发, 打破传统课程教学模式, 构建基于实际工作情景的课程 教学动态知识技能模块, 并以此为基础, 开发以《导游实务》课程教学为例的典型工作任务 为驱动的高职动态课程教学新模式, 为高职旅游专业课程教学提供参考和模型。

关键词：典型工作任务驱动；动态模块；课程教学模式；改革；高职旅游专业

\section{1. 引言}

宾塞在 1859 年提出的 “课程” 就包含了 “学程” 和 “教程” [1]。“学程” 的实施主体是学生, “教程” 实施的主体却是教师和教学组织机构。因此, “教程” 实施的过程中因实施主体的观 点、角度不同对课程目标确立、课程设计、内容选取与组织、课程实施和评价所产生的影响, 形成了不同职业课程开发模式 [2]，如著名的北美 CBE 模式 [3]、德国的 “双元制” 模式 [4]、 澳大利亚 TAFE[5]模式等。尽管我国的教育历史源远流长，但我国 “教程” 科学开发和实施 研究起步很晚, 在上世纪末, 大量引进国外职业课程模式对构建我国职业教育课程体系影响 很大，其中存在大量的水上不服、生搬硬套的现象 [6]。作为我过产业结构中第三产业龙头 产业的旅游行业输送人才的主要基地一一高职旅游教育, 现有的 “学程” 即课程教学模式已 经严重滞后于旅游产业发展和市场的需要, 深入研究旅游专业课程教学体系, 进行专业课程 
教学十分必要。

\section{2. 典型工作任务驱动课程教学模式的内涵}

典型工作任务驱动的高职动态模块化课程教学模式, 打破了学科课程体系的束缚, 从旅游行 业实际工作岗位群的典型工作任务出发, 按完成实际工作任务所需要的知识技能, 将学习过 程、工作过程与学生的个性能力发展联系起来 [3] [8]。为适应高职年龄段学生的社会价值观 以及特有的直观思维特征, 激发学生自主学习兴趣, 设计动态教学模块并安排教学活动, 真实 再现职业情景下的真实的行动领域, 为学生提供了零距离接近真实职业环境下的体验典型工 作过程的学习机会, 有利于学生主动构建自己知识能力体系 [9] [10]。是一种全新的职业教育 课程体系设置思维和实施模式。这种课程模式最显著特征是教学过程与工作过程紧密相连, 融理论模块与动态实践模块于一体, 为学生提供真实的工作情景体验。

\section{3. 高职旅游类专业课程《导游实务》课程教学实施现状}

\section{1. 课程教学实施目标不明确, 教学环节繁琐}

《导游实务》高职旅游管理与服务专业的专业核心课程, 属于理实一体课程。多年来, 专业 教师基本上是没有任何导游实践经验, 课堂教学实施的目标基本是按教材要求设置, 导游实 际工作联系不紧密。因为是理实一体化课程, 缺乏导游实践经验的教师很难实现导游实际工 作情景再现, 在教学实施的环节设置上繁琐凌乱, 教学实效不理想。

3.2. 课程教学设计强调技术技能掌握, 缺乏导游人文素养养成内容

导游服务是一项十分人文化的服务工作，不仅要求导游人员具有扎实的专业技术技能，更重 要的具有强大的人文关怀能力和素养。目前高职乃至本科院校在实施《导游实务》课程教学 设计时, 更多的是强调导游服务的技术技能的掌握, 很少设置人文素养教学内容, 尤其是综 合人文文化素养的内容。

3. 3. 教学内容单一枯燥, 与导游服务实际工作情景有较大差距 高职旅游专业对导游实务的课程教学内容选择是, 更多的是一些工作流程的掌握, 简单机械, 枯燥乏味, 与实际的导游服务工作情景相距较远, 学生学习积极性较低。

3. 4. 理论条目堆砌较多、实践教学设计缺失, 缺乏职业教育特色

大多数导游实务课程教学设计时, 具有典型工作情景意义的实践教学缺失, 多数是长篇理论 堆牍, 缺乏高职教育特色

\section{4. 典型工作任务驱动的高职《导游实务》课程教学模式的改革}

4.1. 导游人才培养的定位

要进行课程改革, 首先要思考是培养什么样的导游员, 怎么培养的问题。即要有明确的课程 教学目标的设计。以典型工作任务驱动的高职《导游实务》课程教学的设计明确的导游实际 工作岗位和职业情景的分析和掌握, 并按照实用的原则, 以职业素养为基础, 以典型工作任 务为驱动, 通过产学研的路径, 培养具有良好职业素养, 以掌握导游实际工作技术技能的合 格的导游服务和旅游管理人才, 以满足旅游市场的需要。 


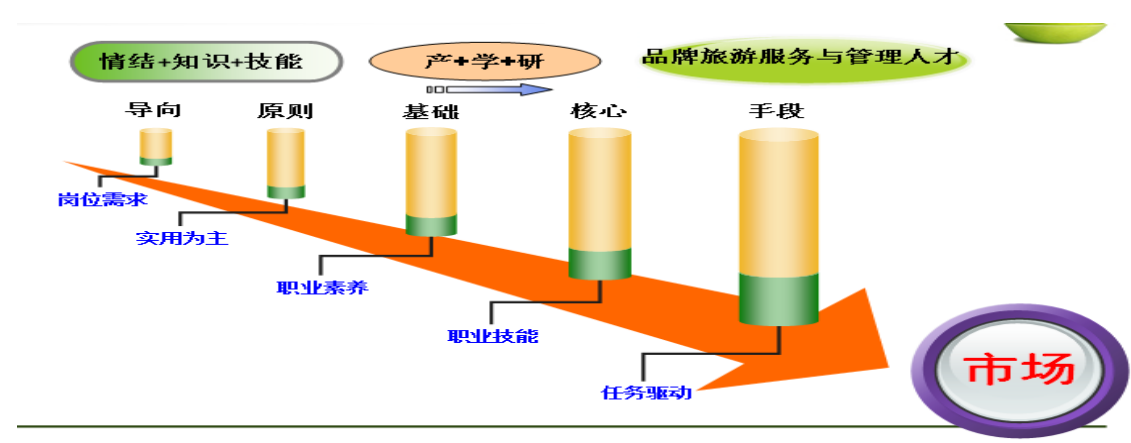

图 1 高职导游人才培养定位

\section{2. 课程教学任务设计定位}

高职旅游专业《导游实务》课程教学任务分七个模块（图 1), 每个模块都将由一系列动态的 知识和技能模块支撑。每个课程任务模块占该课程教学的总任务的比例分别有所呈现 (图 1), 其中工学一体的实训时间任务模块与专业综合技能课程任务模块、专业核心技能课程任务模 块三块实操模块比例综合为 $35 \%+10 \%+15 \%=60 \%$, 而两个理论模块比例和温 $18 \%$, 专业综合素养 课程比例为 $20 \%$ 。总比例结构合理而实现的可能性强, 能够比较好的体现理实一体课程教学 任务的设计。

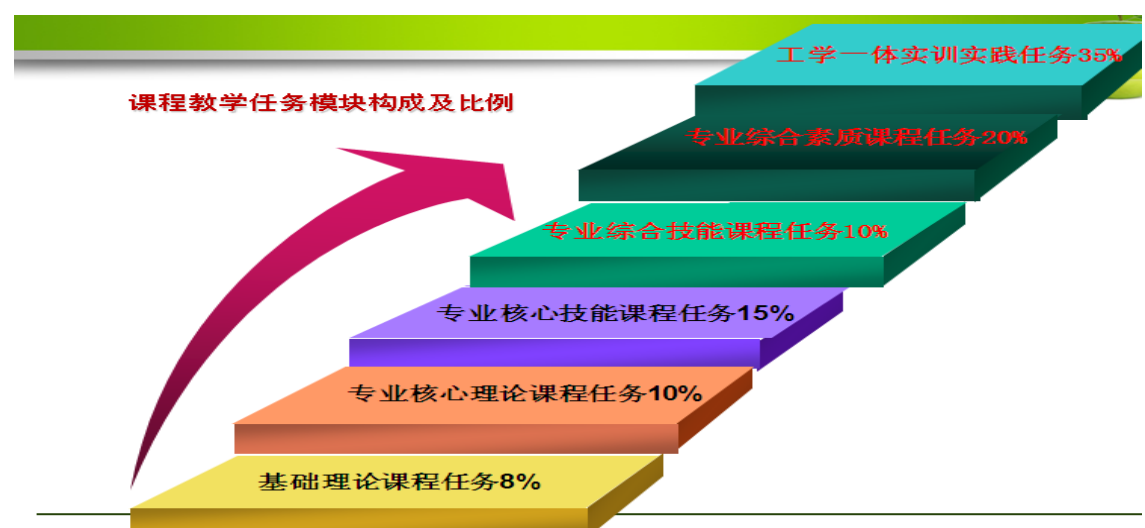

图 2 高职《导游实务》课程教学任务

导游服务工包罗万象，涵盖面很宽，同时还要应付途中突发的各种情况。课程《导游实务》 所涉猎的知识和技能是有限的 (表 1)。要颠覆和打破传统的课程教学模式, 对《导游实务》 知识模块的解构并与导游服务工作的典型工作任务对应起来, 以便对岗位的具体职业情景有 明确的解读和描述

表 1 导游服务工作的典型工作任务和课程《导游实务》部分学习领域对应表

\begin{tabular}{|c|c|c|c|}
\hline 岗位 & 典型工作任务 & 行动领域《导游实务》 & 学习领域 \\
\hline $\begin{array}{l}\text { 导 } \\
\text { 游 } \\
\text { 服 } \\
\text { 务 }\end{array}$ & $\begin{array}{c}\text { *旅行接待、景点讲解、旅游企业 } \\
\text { 或景区形象塑造和宣传 } \\
\text { *落实旅游活动计划, 接待、导游、 } \\
\text { 讲解, 购物服务, 处理突发事件 } \\
\text { *实施旅游接待计划, 处理突发事 } \\
\text { 件 } \\
\text { *组织和团结工作, 监督落实旅游 } \\
\text { 活动计划、翻译、对外宣传、处 } \\
\text { 理跨国应急事件 }\end{array}$ & $\begin{array}{l}* \text { 景点导游 } \\
* \text { *地方导游 } \\
* \text { 全程导游 } \\
* \text { 国际导游 }\end{array}$ & $\begin{array}{l}\text { *导游讲解技巧 } \\
\text { *旅游政策法规 } \\
\text { *导游语言学习 } \\
\text { *导游购物技巧 } \\
\text { *旅游卫生知识与急 } \\
\text { 救 } \\
\text { *导游业务 } \\
\text { *旅游企业形象塑造 } \\
\text { 与维护 }\end{array}$ \\
\hline
\end{tabular}




\section{3. 高职《导游实务》课程教学内容的甄选和动态知识和技能模块重组}

根据表 1 的内容, 要初步完成导游服务的工作, 至少完成以上实际行动领域里众多典型工作, 并且基本掌握《导游实务》中所具有的学习领域。但事实上, 课程《导游实务》现有的教学 内容不仅信息量不够, 而且很多内容随时随市场的变化而不同。因此, 根据具体的教学和学 习内容, 重新解构和重组《导游实务》的教学内容十分必要。设定完成一个完整的导游服务 工作的知识和技能是一个大的工作任务, 构成导游服务学习的内容就包括八个动态模块的学 习任务 (图 3), 这一系列动态模块的学习内容是为了满足导游行动领域里的一系列具体职业 情景而设定的, 并根据具体的教学条件和学生的实际情况做可做相应的调整或者甄选, 同时还 为导游服务工作另外的课程学习提供相应的知识模块, 如旅游文化, 导游基础知识、时事政 策与法规等。

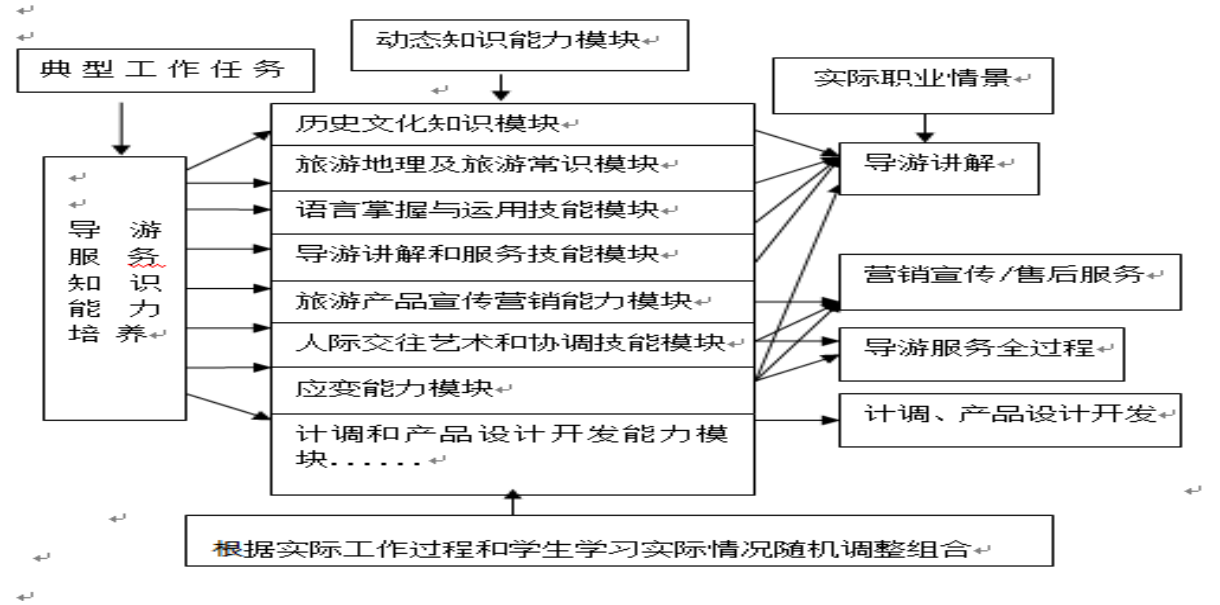

图 3 《导游实务》教学领域所需要的与典型工作任务对应的动态的知识模块

\section{5. 课程《导游实务》课程教学设计的重构}

综上，笔者以 《导游实务》中学习领域《导游服务规程》为例，以典型工作任务为驱动，以 动态知识技能模块为基础, 以实际职业情景为需求, 设计出全新的《导游实务》课程教学设 计模式, 为高职旅游类专业课程教学改革提供了范式。

\section{表 2 典型工作任务为驱动的高职《导游实务》课程教学设计模型}

\begin{tabular}{|c|c|}
\hline 学习领域 & 导游服务规程 \\
\hline *典型工作任务 & 地陪导游服务 \\
\hline *地陪导游服务 & $\begin{array}{l}\text { (1) 基础知识模块: 服务规范和流程; (2)核心技能: 导游讲解、对客服 } \\
\text { 务; (3)拓展技能: 应变应急技巧和方法(4)综合素质模块: 旅游转移过程 } \\
\text { 中服务技能。 }\end{array}$ \\
\hline 识技能动态模 & (1) 掌握地陪导游服务基本流程; (2)了解地陪导游的岗位职责和对客服务 \\
\hline *教学目标 & 拟地陪导游服务实训。 \\
\hline *学习任务 & $\begin{array}{l}\text { 根据地陪导游服务的基本技能和素质要求, 以导游服务四大动态知识技 } \\
\text { 能模块为基础, 熟悉和初步掌握地陪导游服务工作的全过程, 掌握基本 } \\
\text { 的导游对客服务的技术技能, 对旅途突发事件的应急反应有初步的认知。 }\end{array}$ \\
\hline *教学条件 & 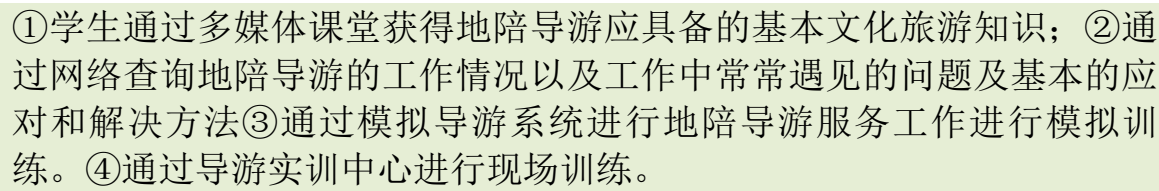 \\
\hline $\begin{array}{l}* \text { * 子 } \\
* \text { *具材料 }\end{array}$ & $\begin{array}{l}\text { 授课计划、学习引导文、多媒体课件、评价表 } \\
\text { 电脑网络、多媒体、导游常用用具、扩音麦、地陪导游工具、社旗、导 }\end{array}$ \\
\hline
\end{tabular}




\begin{tabular}{|c|c|c|}
\hline *其他信息 & \multicolumn{2}{|l|}{ 游册 } \\
\hline *教学阶段 & \multicolumn{2}{|l|}{ 优秀导游案例和事迹 } \\
\hline *下发任务书 & \multicolumn{2}{|c|}{ 教学过程＜wide>教学方法建议＼cjkstart学时 } \\
\hline *决策 & \multicolumn{2}{|c|}{$\begin{array}{lcc}\text { 教师下发任务书, 提出完成本次教学任务的 } & \text { 实地考察法 } & \text { 课外 } \\
\text { 指南, 并就理论学习提出各种问题。(2)教师 } & \text { 案例分析法 } & \end{array}$} \\
\hline & \multicolumn{2}{|l|}{ 在老师的指导下，对提出的工作任务学习方 } \\
\hline $\begin{array}{l}\text { *课程理论学习 } \\
\text { 实施 } 1\end{array}$ & \multicolumn{2}{|l|}{$\begin{array}{l}\text { 案做可靠性、合理性、可操作性等综合分析, } \\
\text { 制定具体的实施计划 }\end{array}$} \\
\hline & $\begin{array}{l}\text { 学生根据自主学习阶段所获得的知识, 按照任务的要 } \\
\text { 求, 列出本模块中的重点知识点, 有针对性的完成地 } \\
\text { 陪导游服务工作流程一一方法一一原则一一讲解技术 } \\
\text { 技能一一应急反应训练一一地陪综合实训一些列知识 }\end{array}$ & $\begin{array}{l}\text { 聚 焦 访 谈 法 } \\
2 \\
\text { 关键词卡片法 } \\
\text { 小组讨论法 }\end{array}$ \\
\hline *实践课程学习 & \\
\hline & \multicolumn{2}{|l|}{$\begin{array}{l}\text { 有关旅行社、旅游实体和旅游互联网站工具使用的资 } \\
\text { 料，开展充分讨论 }\end{array}$} \\
\hline *任务完成检查 & $\begin{array}{l}\text { 依据老师下发的教学资料和学生自主获取的资源, , 并 } \\
\text { 利用专业实训软件进行导游服务模拟训练, 在老师的 }\end{array}$ & \\
\hline & 指导下进行地陪工作的室内外实际工作情景模拟训 & $\begin{array}{l}\text { 个别指导 } \\
\text { 角色扮演法 }\end{array}$ \\
\hline & (3) 师生根据项目和知识模块进行互动训练指导 & 角色扮演法 1 \\
\hline & \multirow{2}{*}{\multicolumn{2}{|c|}{$\begin{array}{l}\text { 案和实施过程的实效及最终效果进行自评, 并根据对 } \\
\text { 每个成员在完成工作的表现和成绩确定贡献值; }\end{array}$}} \\
\hline & \multirow{2}{*}{\multicolumn{2}{|c|}{ (4) 小组互评: 通过被评价小组的介绍以及对设计方案 }} \\
\hline & & \\
\hline & \multicolumn{2}{|l|}{$\begin{array}{l}\text { 的阅读, 对其他小组的成果进行评价 } \\
\text { (5) 教师评价: 教师对根据每个小组在完成任务时的集 } \\
\text { 休表䚮和丁作方安的伏少对该学习项目宗成的效里讲 }\end{array}$} \\
\hline & \multirow{2}{*}{\multicolumn{2}{|c|}{$\begin{array}{l}\text { 体表现和工作方案的优劣对该学习项目完成的效果进 } \\
\text { 行评价。 } \\
\text { 对教师的建议和评价。 }\end{array}$}} \\
\hline & & \\
\hline
\end{tabular}

\section{6. 结语}

当前, 传统的高职课程教学模式已经滞后于高职旅游教育的发展和旅游产业发展的需要。对 传统课程教学模式进行改革已是迫在眉睫。本研究拟以旅游管理专业核心课程《导游实务》 为例, 以实际职业行动领域所需为基础, 以典型工作为驱动, 按找职业岗位所需设计动态课 程教学的知识和技能模块, 开发出新的《导游实务》课程教学设计模型, 充分调动学生的学 习自主性和教学的积极能动性, 实现课程教学和实际工作行动领域的要求形成知识技能的零 距离对接, 为高职旅游专业课程改革提供范式和模型。

\section{7. 致谢}

【基金项目】本研究受湖南省教育教改重点项目（ZJA2013018）; 湖南省教育科学十二. 五规 划课题（XJK014CZY039）基金支持。

\section{参考文献}

[1] 姜大源. 当代世界职业教育发展趋势研究[M], 2013.8, p.(145-145) 
[2] 张玉香. 高职旅游类课程体验式实训教学模式研究---- 以《导游业务实训》为例, 内蒙古 农业大学学报(社会科学版) [J], 2012.02,p.(169-171)

[3] 刘占明.基于工作过程导向的高职旅游类专业课程体系创新研究, 河北师范大学硕士论文 [D], 2009.8, 20, p.(14-20)

[4] 徐玉岩. 基于项目驱动的高职 “于项目驱动的高职与 Linux 操作系统” 课程教学改革,计 算机教育[J], 2010.9(18), p(25-27).

[5] Information on http://www.bibb.de [EB/OL

[6] 蒋方纯.现代职业教育课程教学构建策略, 2013深圳国际社会科学、心理学和管理学大会, 2013.1, p.(231-236).

[7] 姜大源.再释德国双元制职业教育体系，中国职业技术教育2013.1, p.21-30.

[8] 何荣誉, 单武雄, 白长城. 面向岗位能力的中高职课程体系衔接探究----以数控专业为例, 职 业技术教育[J], 2014.02, p. (34-37).

[9] 谭文培.英、澳、美中高职衔接课程体系的构建及对我国的借鉴,科教文汇(下旬刊) [J], 2014.07, p.( 116-117).

[10]何静.基于职业综合能力的高职人才培养模式的研究, 中国成人教育[J], 2013.08, p.(95-97).

\section{Acknowledgement}

This research was financially supported by the 2013Important Research Project of Higher Education Reform in Hunan (ZJA2013018) and the 2014Educational Scientific Subject of Hunan Twelfth Five Years Plan (XJK014CZY039J).

\section{References}

[1] Jiang Dayuan. Three Basic Questions to Build a Modern Vocational Education System, Guangzhou Vocational Education Forum 2012.1, P.5-7.

[2] Zhang Yuxiang. Research on the Experiential Training Teaching Mode of Tourism Courses in Higher Vocational Colleges -A Case of the Practical Training of Tour Guide Service Journal of Inner Mongolia Agricultural University (Social Science Edition), 2012.02, P. (169-171).

[3] Liu Zhanmin. Creative Research on Course System of Major of High-Level Vocational Tourism Based on Working Process, Heibei Normal University, 2009.8, 20, P.(14-20).

[4] Xu Yuyan. Tending Reform of Windows and Linux Operarting Systems in Higher Vocation Education Based on Project Driven. Computer Education (2010.9), P.25-27.

[5] Information on http://www.Bibb. De [EB/OL].

[6] Jiang Fangchun. Modern Vocational Education Course Teaching Building Strategy, 2013 International Conference on Psychology, Management And Social Science, Shenzhen, China(PMSS 2013), 2013.1, P.212-215.

[7] Jiang Dayuan Reinterpretation of Vocational Education of Double Competence System in Germany, Chinese Vocation and Technical Education 2013.1, P21-30.

[8] He Rongyu, Shan Wuxiong, Bai Changcheng. Research on the Linkage of Curriculum System of Secondary and Higher Vocational Education Based on Post Abilities---The Case of Numerical Control Specialty Vocational and Technical Education, 2014.02, P (34-37). 
[9] Tan Wenpei. The Construction of Bridging Curriculum System for Secondary and Higher Vocational Education in Britain, Australia and America and Its Enlightenment to China // The Science Education Article Collects, [J], 2014.07, P. (116-117).

[10]He Jing. Research on Culturing Mode of the Talent in Higher Vocational Education Based on Comprehensive Vocational Ability China Adult Education [J], 2013.08, P. (95-97).

作者简介: 刘韵琴 (1970-), 女, 湖南永州, 教授, 主要研究方向: 职业教育, 生态旅游。 邮箱: 1yq521125@126.com 